\title{
Quality of life, diagnosis, and treatment of patients with major depression: a prospective cohort study in primary care
}

\section{Qualidade de vida, diagnóstico e tratamento de pacientes com depressão maior: uma coorte prospectiva em cuidados primários}

\author{
Ana Flávia Barros da Silva Lima, ${ }^{1}$ Marcelo Pio de Almeida Fleck ${ }^{2}$ \\ 1 Post-Graduate Psychiatry Program, Universidade Federal do Rio Grande do Sul (UFRGS), Porto Alegre, RS, Brazil \\ ${ }^{2}$ Department of Legal Medicine and Psychiatry, Universidade Federal do Rio Grande do Sul (UFRGS), Porto Alegre, RS, Brazil
}

Abstract

Objective: To describe the demographic and clinical characteristics, adequacy of antidepressant treatment, and changes in quality of life of patients with major depression receiving follow-up care from primary care centers. Method: A cohort study was performed in which major depression patients were followed-up over a nine-month period. Several evaluation instruments were used, including the World Health Organization Quality of Life and the Quality of Life-Depression, Centers for Epidemiologic Studies-Depression questionnaires. Results: The sample comprised 179 individuals, mostly female (73\%), with a mean age of 38 years and mean education of 9 years. At the end of the follow-up period, $42 \%$ of the individuals still presented with major depression, $25 \%$ had complete symptom remission, and only $9 \%$ were properly treated with antidepressants. In relation to quality of life, there were significant differences especially between baseline and after nine months in almost all measures. Conclusion: This study demonstrated that depressive symptoms are poorly recognized and that treatment is often inadequate for patients followed-up in primary care units in the south of Brazil. Most of the patients continued to have symptoms of depression over the nine-month period which were associated with impaired quality of life.

Descriptors: Quality of life; Diagnosis; Depressive disorder, major; Primary health care; Signs and symptoms

\section{Resumo}

Objetivo: Descrever o seguimento de usuários de serviços de cuidados primários com depressão maior em relação as suas características demográficas, clínicas, tratamento antidepressivo potencialmente adequado, assim como mudanças encontradas na qualidade de vida ao longo do acompanhamento. Método: Foi realizado um estudo de coorte, no qual os sujeitos com depressão maior foram acompanhados ao longo de nove meses. Foram incluidas diversas medidas de avaliação, como World Health Organization Quality of Life, Quality of Life-Depression, Centers for Epidemiologic StudiesDepression Instrument, entre outras. Resultados: A amostra foi constituida por 179 sujeitos, a maioria do sexo feminino (73\%), com uma idade média de 38 anos e 9 anos de escolaridade. Aos nove meses do estudo, 42\% dos sujeitos ainda apresentavam um quadro compativel com depressão maior, $25 \%$ com remissão completa dos sintomas e somente $9 \%$ foram tratados com antidepressivo de forma adequada. Em relação à qualidade de vida, ocorreram diferenças significativas principalmente entre o periodo de baseline e nove meses para quase todas as medidas. Conclusão: Este estudo demonstrou que pacientes com sintomas depressivos dificilmente são reconhecidos ou recebem tratamentos adequados em unidades de cuidados primários no sul do Brasil. A grande maioria dos pacientes permaneceu com sintomas depressivos ao longo dos nove meses, apresentando prejuizos na qualidade de vida.

Descritores: Qualidade de vida; Diagnóstico; Transtorno depressivo maior; Atenção primária à saúde; Sinais e sintomas

\section{Introduction}

Recent studies with depressed patients in primary care settings have demonstrated that these patients have several depressionrelated problems such as high rates of comorbidity, low functional levels, and increased use of medical resources. ${ }^{1,2}$ Despite their strong impact on the patients' lives, the recognition of depressionrelated problems is still poor in the primary sector, where $50 \%$ to $60 \%$ of the cases are not detected and do not receive adequate and specific treatment. ${ }^{1-3}$
Several studies have demonstrated the impact of depression on quality of life (QOL), with depressed patients displaying QOL impairments which are equal to or greater than those of patients with other chronic conditions. ${ }^{4-6}$ Another relevant aspect of this association is that the severity of the depressive disorder affects all QOL dimensions, even when controlled for other variables such as age. ${ }^{7,8}$ Although this association is well-established, most of the measures come from cross-sectional studies that do not 
permit an understanding of the causal relationship between the variables involved.

There are few observational studies or clinical tests with antidepressants based on the longitudinal investigation of the associations between depression and QOL measures in primary care. ${ }^{8-14}$ There is evidence suggesting the existence of a time gap between changes in depressive symptoms and QOL measures. In other words, the improvement in symptoms and in quality of life do not occur simultaneously, but rather at different times. ${ }^{8,13-15}$

The objective of this study is to describe the characteristics of a sample of Brazilian individuals with major depression seeking treatment in primary care units, as well as any changes in QOL over a nine-month follow-up period and its relation with antidepressant treatment.

\section{Method}

This study was carried out using a cohort obtained from the Longitudinal Investigation of Depression Outcomes (LIDO) study, the methodology of which is described below.

\section{Description}

The LIDO project was a multi-center cohort study carried out in six centers (Australia, Brazil, Spain, Israel, United States, and Russia) where primary care service users presenting with a diagnosis of major depressive disorder - current episode were accompanied for a one-year period.

This article describes the results of a cohort study based exclusively on data from the follow-up of Brazilian patients. The study was approved by the ethics committees of the Hospital de Clinicas and the Hospital Conceição, both in Porto Alegre, Brazil.

\section{Sample selection}

A screening interview was performed with 2,475 users of three primary care services in Porto Alegre that participated in the study in a consecutive manner, starting with their arrival at the health center between August 1998 and March 1999. The individuals were initially screened for depression using the Center for Epidemiologic Studies Depression Scale (CES-D; Radloff et al., 1977). Individuals with a CES-D score $\geq 16$ were invited for a more detailed interview to confirm a recent major depressive episode. This interview (called "baseline") was held up to two weeks after the initial contact by trained interviewers. The diagnosis of depression was confirmed in this interview using the Composite International Diagnostic Interview (CIDI).

Individuals who were diagnosed as having current major depression according to the CIDI (CIDI+), aged 18 to 75 , living in the geographical area of the health center, and available over the next 12 months were invited to participate in the follow-up study. Individuals in treatment for depression or who had been in treatment up to three months before the study, those presenting with any psychiatric disorders such as psychosis or organic cerebral syndromes, and those who had any other condition that the main investigator felt could interfere in the study were excluded. Participants were assessed at baseline, six weeks, and three and nine months after baseline. After confirmation of the depression diagnosis, the physician responsible for the patient's care was informed by letter of the probable diagnosis of major depression. The decision to treat the depressive episode was left exclusively to the attending physician, since the study had a naturalistic observation design.

\section{Definition of potentially adequate antidepressant treatment}

Potentially adequate antidepressant treatment was defined as treatments based on the smallest doses recommended by the U.S. Agency for Health Care Policy and Research Guidelines for the Treatment of Depression in Primary Care (for example, $75 \mathrm{mg}$ of imipramine or $20 \mathrm{mg}$ of fluoxetine).

\section{Instruments}

Center for Epidemiologic Studies - Depression Scale (CES-D): The CES-D is a 20-item scale that has the objective of measuring depression symptoms in community populations. ${ }^{16}$ It is useful to screen for symptoms of depression, but not for confirming diagnosis. The subject answers questions based on the week preceding the evaluation using a four-point scale ranging from 0 (rarely) to 3 (most of the time). The total score is calculated using a simple sum that varies from 0 to 60 . The cutoff point considered to differentiate individuals with symptoms of depression is $16 .^{16}$

Quality of Life Depression Scale (QLDS): The QLDS is a specific measure of QOL for patients with depression. It consists of 34 items rated as true or false. False answers indicate an adverse effect on QOL, whereas true answers indicate a positive impact on QOL. The scores vary from 0 (good QOL) to 34 (poor QOL). ${ }^{17}$

Composite International Diagnostic Interview (CIDI): The CIDI is a structured interview developed to detect a variety of mental problems in primary care settings. This study used the depression module version 2.1. ${ }^{18}$

Brief version of the World Health Organization instrument to assess quality of life (WHOQOL-BREF): This is a reduced version of the 100-question World Health Organization instrument designed to assess QOL, the WHOQOL-100. This instrument was conjointly developed at 15 international centers and has been validated for the Portuguese language. The reduced version, with 26 questions, encompasses four domains (physical, psychological, social relations, and environment). There are four scales to assess intensity, capacity, frequency, and evaluation, with scores ranging from zero to four. In each scale, the scores range from 0 to 100 , with higher scores suggesting better quality of life. ${ }^{19,20}$

Medical Outcomes Study Short-Forms (SF-12) and MHI-5 subscales of the SF-36: The SF-12 is an abbreviated version of the SF-36, with 12 items that assess two dimensions: physical and mental. The SF-36 is an instrument that assesses functional status and well-being and is divided into eight areas (physical functions, physical role limitations, emotional role limitations, social functioning, bodily pain, general mental health, vitality, 
and general health perceptions). Scores range from 0 to 100 in each area. The MHI-5 is a subscale of the SF-36, consisting of five items that assess mental health. ${ }^{21}$

Use of Health Resources: Identifies the use of health resources in three categories: primary care or outpatient service, day hospital, and in-patient service. It also describes the use of medications during the follow-up period. ${ }^{22}$

\section{Statistical analysis}

The chi-square test was used to compare category variables. A $t$ test was used to compare continuous variables for dependent samples.

Mixed models were used for repeated-measures analysis with the visit as a fixed effect and diagonal variance-covariance matrix for comparison between groups.

\section{Results}

The sample consisted of 179 individuals, mostly female (73\%), with a mean age of 38 years and mean education of 9 . The other demographic and clinical characteristics recorded in the baseline visit are described in Table 1 . At the end of the nine-month follow-up, $42 \%$ of the individuals still presented major depression (CIDI+), 68\% presented depressive symptoms (CES-D $\geq 16$ ), and only $25 \%$ presented complete symptom remission (CIDI- and CES-D < 16). In relation to treatment, $73 \%$ of the patients did not receive any treatment during the study and only $9 \%$ were adequately treated with antidepressants. With regard to QOL, at the beginning of the study, $54.2 \%$ considered it to be good or very good, whereas $50.3 \%$ considered it to be good or very good at the end of the follow-up period, with no significant differences between these measurements.

Still concerning QOL, there were significant differences in almost all measures between the baseline visit and the final assessment and between the 6 -week visit and the final assessment. Only the overall domain presented no significant differences between visits. The variation in the average WHOQOL scores was greater for the physical domain $(55.6$ to 64.9) and smaller for the environmental domain (50.30 to
54.14). The mean QOL and CES-D scores are described in Figures 1 and 2, respectively.

\section{Discussion}

This study presents two main findings. First, depression symptoms were poorly identified and poorly treated in the primary care network. At the end of the study, $42 \%$ of the individuals still presented major depression, and only $9 \%$ were in adequate treatment with antidepressants. Second, individuals with depression presented little improvement in QOL measures throughout the nine-month follow-up. The biggest difference in relation to the mean QOL scores was found between baseline and the nine-month visit, demonstrating that any changes occurring in these patients' life are not quickly observable.

In relation to the sample's clinical characteristics, $68 \%$ persisted with important symptoms of depression at the end of the study. The mean baseline CES-D score was 32 points, falling to 23 points at the last follow-up visit, with a small effect size between these measures. Another important fact is that only $27 \%$ of the individuals received any type of treatment such as counseling or medication for depression, and only $9 \%$ were adequately treated with antidepressants. It is important to underscore that the attending physicians were informed by letter of a probable diagnosis of depression identified by a standardized diagnostic instrument by the researchers. Thus, the data obtained in this study suggest that these subjects were either not identified as having depression symptoms - although the physicians had been advised about the probable diagnosis -, that their physicians prescribed no proper treatment, or that these patients had difficulties accessing the health resources available.

The poor detection of depression symptoms found here is in agreement with previous evidence suggesting that $51 \%$ of the patients treated in primary care continue to have these symptoms, and that only some years later are they referred to specialized care. ${ }^{23}$ The benefits of the treatment with antidepressants have been broadly demonstrated in the literature through clinical trials and in studies like the one by Skevington et al., where $74 \%$ of the participants received treatment with adequate antidepressants

Table 1 - Demographic data and clinical characteristics at baseline

\begin{tabular}{llc}
\hline & Data type & \multicolumn{1}{c}{ Variables } \\
\hline Demographic & Women (\%) & $135(72.9)$ \\
& Mean age (SD) & $38.50(14.13)$ \\
& Mean education (SD) & $9.12(3.42)$ \\
& Marital status & $93(52.2)$ \\
& Married (\%) & $44(24.7)$ \\
& Single (\%) & $33(18.6)$ \\
\hline Clinical & Employment status & $71(40)$ \\
& Unemployed (\%) & $86(56)$ \\
& Employed (\%) & $4(2.03)$ \\
\end{tabular}


for an eight-week period and showed improvements in QOL. ${ }^{24}$ Beyond the medical perspective, there is also evidence that the therapy with antidepressants reduces the indirect costs of depression by decreasing the number of workdays lost and increasing productivity. ${ }^{25}$

Therefore, the low rate of complete remission in our study, of around $25 \%$, is probably mainly due to the difficulty in identifying the diagnosis of depression, as well as the lack of appropriate treatment.

There is a great variability in relation to the remission indexes found in previous studies, with rates ranging from $24 \%$ to $68 \% .^{9,10,26-29}$ The recruitment of different populations, as well as the diversity of instruments and criteria used to evaluate remission, probably contribute to these differences. ${ }^{26}$ In relation to the other centers that participated in our study, our center had the lowest rate of remission, compared to $32 \%$ in St. Petersburg and $48 \%$ in Barcelona. This probably occurred due to the two abovementioned factors (non-identification of cases or inadequate treatment) or to the difficulty in the access to the health resources available. Vinamaki et al. performed a two-year follow-up study about the recovery from symptoms of depression in which $65 \%$ of the participants remained depressive, with the insufficient use of health services as a significant factor associated with nonrecovery. ${ }^{26}$

This variable deserves a more detailed study since Brazil has serious problems regarding the access to health resources and to specialized treatment, especially due to economic barriers. ${ }^{30}$ Previous studies show that the costs of medication, the difficulties to obtain specialized care, and the barriers to reach healthcare units (long distances and transportation issues) are preponderant factors hindering the access to adequate treatment. ${ }^{21,31}$ Additionally, there is a number of variables that affect the treatment and that have complex interactions which are not fully understood to date, such as the perception, attitudes, and preferences of patients regarding depression and its treatment and the attitudes and training of physicians, all of which are likely to have an influence on the adherence to the treatment and the outcomes of therapeutic interventions. ${ }^{21,31,32}$

Concerning the assessment of QOL, all measures showed little change over the nine-month period, with small effect sizes between baseline and the final visit. In relation to the WHOQOL-BREF, the major differences were found in the physical, psychological, and social dimensions. Since the participants were selected while seeking medical care and since $95 \%$ of them had some clinical comorbidity, it is probable that the presence of these clinical conditions also had an impact on QOL, especially in what concerns the physical domain. In this study the authors used the SF-36 subscale and the WHOQOLBREF because they measure different aspects of QOL and can function as complementary questionnaires. The WHOQOL$\mathrm{BREF}$ is a generic measure of QOL and refers to the well-being of the individual, and the SF-36 is a health-related QOL measure that gauges functional status. Another aspect that must have contributed to the small improvement in QOL is the persistence of depression symptoms at the end of the study. This is in agreement with earlier evidence showing that emotional status exerts a great impact on QOL assessments, with a resulting variance of $20 \%$ in the overall WHOQOL scores, and that persistent negative mood affects all the domains measured by the WHOQOL. ${ }^{33,34}$
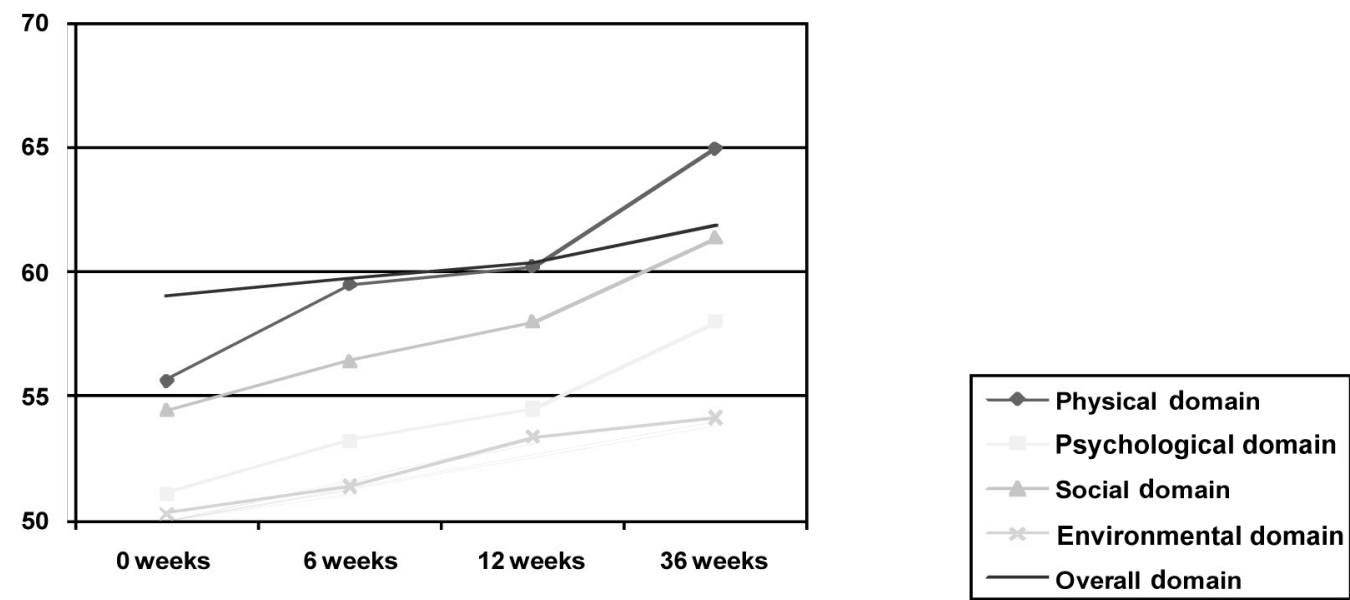

Figure 1 - Mean scores for WHOQOL domains measured at baseline, 6 weeks, 3 months, and 9 months. ES in physical domain was 0.49 between baseline and 9 months and 0.33 between baseline and 9 months. ES in psychological domain was 0.37 between baseline and 9 months and 0.26 between 6 weeks and 9 months. ES in social domain was 0.31 between baseline and 9 months and 0.22 between 6 weeks and 9 months. ES in environmental domain was 0.31 between baseline and 9 months and 0.22 between 6 weeks and 9 months. There was no significant difference between the overall domain scores over the 9 months. 


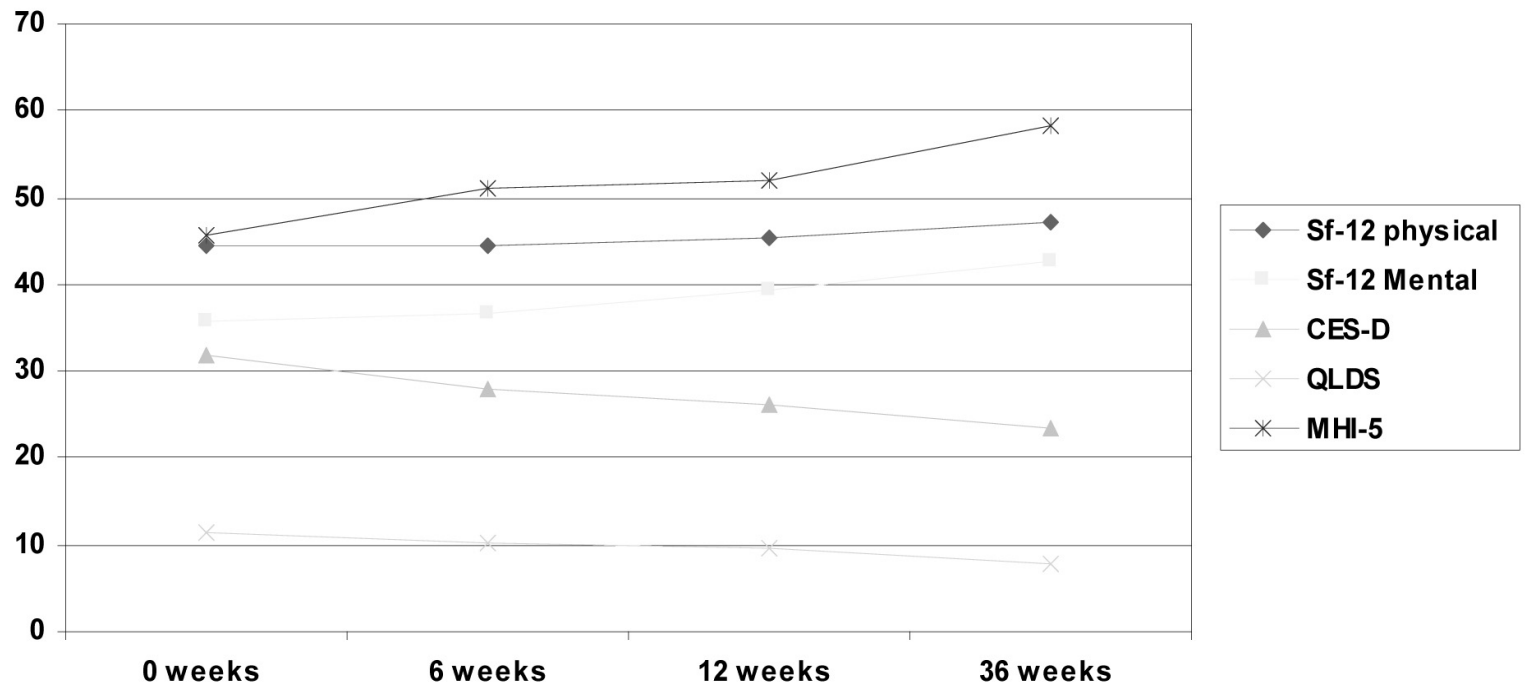

Figure 2 - Mean scores for the SF-12 physical and mental, CES-D, QLDS, and MHI-5 instruments measured at baseline, 6 weeks, 3 months, and 9 months.

ES in SF-12 physical was 0.29 between baseline and 9 months and 0.31 between 6 weeks and 9 months.

ES in SF-12 mental was 0.48 between baseline and 9 months and 0.28 between 6 weeks and 9 months.

ES in CES-D was 0.56 between baseline and 9 months and 0.28 between 6 weeks and 9 months.

ES in QLDS was 0.43 between baseline and 9 months and 0.30 between 6 weeks and 9 months.

ES in MHI- 5 was 0.48 between baseline and 9 months and 0.28 between 6 weeks and 9 months.

Our study had some limitations. The participants were selected while seeking assistance at primary healthcare units. Therefore, the sample probably comprised individuals with light to moderate depression, which restricts the generalization of these data to samples with more severe depression or seeking specialized services. Furthermore, the comparison of data related to QOL is further hampered by other factors. First, although the association between QOL and depression has already been extensively demonstrated in the literature, ${ }^{35-39}$ there are few studies in Latin America investigating this association with the same instruments used in this study. ${ }^{40,41}$ The WHOQOL has already been validated to several languages, but it is still little used in psychiatry, with only 12 articles assessing QOL in patients with major depression over the past 10 years. There is also a lack of normative data for QOL-related instruments such as the WHOQOL and the QLDS. All these factors make it difficult to interpret our results as well as to establish cutoff points for the comparison between measures.

Another aspect to be considered in the interpretation of the findings presented here is that most of the previous studies were cross-sectional, thus not permitting a better understanding of the association between QOL and depression. Naturalistic follow-up studies involving individuals with depression in the community or in primary care settings are scarce, generally covering a short period of time and comprising patients referred to specialized treatment. ${ }^{9}$ Over the past 10 years, there has been a growing interest in the study of variables related to QOL, with a more

Table 2 - Mixed model analysis

\begin{tabular}{lcccc}
\hline \multicolumn{1}{c}{ Effect } & Num df & Denominator df & F & Sig \\
\hline WHOQOL Phys & 3 & 302.58 & 8.27 & 0.00 \\
WHOQOL Psych & 3 & 303.86 & 5.64 & 0.001 \\
WHOQOL Social & 3 & 301.04 & 3.82 & 0.01 \\
WHOQOL Enviro & 3 & 288.27 & 3.01 & 0.030 \\
WHOQOL Overall & 3 & 289.72 & 0.767 & 0.513 \\
SF-12 Phys & 3 & 292.88 & 2.956 & 0.033 \\
SF-12 Mental & 3 & 291.17 & 11.18 & 0.000 \\
CES-D & 3 & 302.98 & 15.02 & 0.000 \\
QLDS & 3 & 310.15 & 5.40 & 0.001 \\
MHI-5 & 3 & 283.99 & 10.74 & 0.000 \\
\hline
\end{tabular}

Adjustment for multiple comparisons: Less significant difference. 
expressive number of one-year or longer follow-ups. However, there is still much confusion in the articles with regard to the concepts of QOL, recovery, and remission of symptoms, which in turn leads to confounding conclusions. ${ }^{42}$

\section{Conclusion}

This study demonstrated that patients with symptoms of depression are poorly diagnosed and rarely receive adequate treatment in primary care units in the south of Brazil. Most of the patients continued to have symptoms of depression over the ninemonth period of the study, with consequent QOL impairments. Since primary care services are generally the most used means of access to health care, especially in a country lacking specialized service, the non-detection of depressive disorders, as well as the non-provision of specific and adequate treatment, may cause important problems for the clinical evolution of depression and for QOL, potentially increasing indirect costs to society in general. This study warns of the need to implement training measures for health professionals in primary care settings so that they are able to detect and treat this disorder at an early stage and improve the QOL of individuals suffering from these symptoms.

\section{Acknowledgements}

The data described in this paper are part of the multicenter "Longitudinal Investigation Depression Outcome" study (LIDO). The authors thank Eli Lilly and Company for sponsoring the research and the Fundo de Incentivo à Pesquisa e Eventos do Hospital de Clínicas de Porto Alegre (FIPE/HCPA).

\section{Disclosures}

\begin{tabular}{|c|c|c|c|c|c|c|c|}
\hline $\begin{array}{l}\text { Writing group } \\
\text { member }\end{array}$ & Employment & $\begin{array}{l}\text { Research } \\
\text { grant }^{1}\end{array}$ & $\begin{array}{l}\text { Other research grant } \\
\text { or medical continuous } \\
\text { education }^{2}\end{array}$ & $\begin{array}{l}\text { Speaker's } \\
\text { honoraria }\end{array}$ & $\begin{array}{l}\text { Ownership } \\
\text { interest }\end{array}$ & $\begin{array}{l}\text { Consultant/ } \\
\text { Advisory } \\
\text { board }\end{array}$ & Other ${ }^{3}$ \\
\hline $\begin{array}{l}\text { Ana Flávia Barros da } \\
\text { Silva Lima }\end{array}$ & UFRGS & - & - & - & - & - & - \\
\hline Marcelo P. Fleck & UFRGS & FIPE/HCPA* & - & - & - & - & - \\
\hline \multicolumn{8}{|c|}{$\begin{array}{l}\text { * Modest } \\
\text { ** Significant } \\
\text { *** Significant. Amounts given to the author's institution or to a colleague for research in which the author has participation, not directly to the } \\
\text { author. } \\
\text { Note: UFRGS = Universidade Federal do Rio Grande do Sul; FIPE/HCPA = Fundo de Incentivo à Pesquisa e Eventos do Hospital de Clínicas } \\
\text { de Porto Alegre. }\end{array}$} \\
\hline
\end{tabular}

\section{References}

1. Wells KB, Manning WG Jr, Valdez RB. The effects of insurance generosity on the psychological distress and psychological well-being of a general population. Arch Gen Psychiatry. 1989;46(4):315-20.

2. Wells KB, Golding JM, Burnam MA. Psychiatric disorder in a sample of the general population with and without chronic medical conditions. Am J Psychiatry. 1988;145(8):976-81.

3. McQuaid JR, Stein MB, Laffaye C, McCahill ME. Depression in a primary care clinic: the prevalence and impact of an unrecognized disorder. J Affect Disord. 1999;55(1):1-10.

4. Wells KB, Sherbourne CD. Functioning and utility for current health of patients with depression or chronic medical conditions in managed, primary care practices. Arch Gen Psychiatry. 1999;56(10):897-904.

5. Spitzer RL, Kroenke K, Linzer M, Hahn SR, Williams JB, deGruy FV 3rd, Brody D, Davies M. Health-related quality of life in primary care patients with mental disorders. Results from the PRIME-MD 1000 Study. JAMA. 1995;274(19):1511-7.

6. Bonicatto SC, Dew MA, Zaratiegui R, Lorenzo L, Pecina P. Adult outpatients with depression: worse quality of life than in other chronic medical diseases in Argentina. Soc Sci Med. 2001;52(6):911-9.

7. Ravindran AV, Matheson K, Griffiths J, Merali Z, Anisman H. Stress, coping, uplifts, and quality of life in subtypes of depression: a conceptual frame and emerging data. J Affect Disord. 2002;71(1-3):121-30.

8. McCall WV, Cohen W, Reboussin B, Lawton P. Effects of mood and age on quality of life in depressed inpatients. Affect Disord. 1999;55(2-3):107-14.

9. Van Weel-Baumgarten EM, Schers HJ, van den Bosch WJ, van den Hoogen HJ, Zitman FG. Long-term follow-up of depression among patients in the community and in family practice settings. A systematic review. J Fam Pract. 2000;49(12):1113-20.
10. Ezquiaga E, Garcia-Lopez A, de Dios C, Leiva A, Bravo M, Montejo J. Clinical and psychosocial factors associated with the outcome of unipolar major depression: a one year prospective study. J Affect Disord. 2004;79 (1-3):63-70.

11. Koivumaa-Honkanen H, Honkanen R, Antikainen R, Hintikka J, Laukkanen E, Honkalampi K, Viinamäki H. Self-reported life satisfaction and recovery from depression in a 1-year prospective study. Acta Psychiatr Scand. 2001;103(1):38-44. 12. De Almeida Fleck MP, Simon G, Herrman H, Bushnell D, Martin M, Patrick D; Longitudinal Investigation of Depression Outcomes Group. Major depression and its correlates in primary care settings in six countries.9-month follow-up study. Br J Psychiatry. 2005;186:41-7.

13. Diehr PH, Derleth AM, McKenna SP, Martin ML, Bushnell DM, Simon G, Patrick DL. Synchrony of change in depressive symptoms, health status, and quality of life in persons with clinical depression. Health Qual Life Outcomes. 2006;4:27. 14. Berlim MT, Fleck MP. Quality of life and major depression: current findings and future perspectives. In: Ritsner MS, Awad G, editors. Quality of life impairment in schizophrenia, mood and anxiety disorders: New perspectives on research and treatment. Berlim: Springer; 2007. p.241-52.

15. Papakostas GI, Petersen T, Mahal Y, Mischoulon D, Nierenberg AA, Fava M. Quality of life assessments in major depressive disorder: a review of the literature. Gen Hosp Psychiatry. 2004;26(1):13-7.

16. Radloff LS. The CES-D scale: a self-report depression scale for research in the general population. Appl Psychol Meas. 1977;1:385-401.

17. Hunt SM, McKenna SP. The QLDS: a scale for the measurement of quality of life in depression. Health Policy. 1992;22(3):307-19.

18. Weiller E, Lecrubier Y, Maier W, Ustun TB. The relevance of recurrent brief depression in primary care. A report from the WHO project on Psychological Problems in General Health Care conducted in 14 countries. Eur Arch Psychiatry Clin Neurosci. 1994;244(4):182-9. 
19. Fleck MP, Louzada S, Xavier M, Chachamovich E, Vieira G, Santos L, Pinzon V. Application of the Portuguese version of the abbreviated instrument of quality of life WHOQOL-bref. Rev Saude Publica. 2000;34(2):178-83.

20. The WHOQOL GROUP. Development of the World Health Organization WHOQOL-BREF quality of life assessment. Psychol Med. 1998;28(3):551-8.

21. Ware JE Jr, Sherbourne CD. The MOS 36-item short-form health survey (SF36). I. Conceptual framework and item selection. Med Care. 1992;30(6):473-83. 22. Beechmam JK, Knapp MRJ. In: Wing J, Thornicroft G, Brewin C, editors. Costing psychiatric interventions. Measuring mental health needs. London: Gaskell; 1992.

23. Paykel ES, Watters L, Abbott R, Wadsworth M. Do treated psychiatric patients become later community cases? A prospective cohort study. Eur Psychiatry. 2006;21(5):315-8.

24. Skevington SM, Wright A. Changes in the quality of life of patients receiving antidepressant medication in primary care: validation of the WHOQOL-100. Br J Psychiatry. 2001;178:261-7.

25. von Knorring L, Akerblad AC, Bengtsson F, Carlsson A, Ekselius L. Cost of depression: effect of adherence and treatment response. Eur Psychiatry. 2006;21(6):349-54

26. Viinamäki $H$, Tanskanen A, Honkalampi K, Koivumaa-Honkanen $H$, Antikainen R, Haatainen K, Hintikka J.Recovery from depression: a two-year follow-up study of general population subjects. Int J Soc Psychiatry. 2006;52(1):1928.

27. Goldberg JF, Harrow M. Consistency of remission and outcome in bipolar and unipolar mood disorders: a 10-year prospective follow-up. J Affect Disord. 2004;81(2):123-31

28. Kuehner C, Buerger C. Determinants of subjective quality of life in depressed patients: the role of self-esteem, response styles, and social support. J Affect Disord. 2005;86(2-3):205-13

29. Skãrsãter I, Baigi A, Haglund L. Functional status and quality of life in patients with first-episode major depression. J Psychiatr Ment Health Nurs. 2006;13(2):205-13.

30. Simon GE, Fleck M, Lucas R, Bushnell DM; LIDO Group Prevalence and predictors of depression treatment in an international primary care study. $\mathrm{Am} \mathrm{J}$ Psychiatry. 2004;161(9):1626-34.

31. Simon GE, Goldberg D, Tiemens BG, Ustun TB. Outcomes of recognized and unrecognized depression in an international primary care study. Gen Hosp Psychiatry. 1999;21(2):97-105.

32. Weich S, Morgan L, King M, Nazareth I. Attitudes to depression and its treatment in primary care. Psychol Med. 2004;37(9):1239-48.

33. Heinonen $\mathrm{H}$, Aro AR, Aalto AM, Uutela A. Is the evaluation of the global quality of life determined by emotional status? Qual Life Res. 2004;13(8):1347-56.

34. Picardi A, Rucci P, de Girolamo G, Santone G, Borsetti G, Morosini P. The quality of life of the mentally ill living in residential facilities: findings from a national survey in Italy. Eur Arch Psychiatry Clin Neurosci. 2006;256(6):372-81.

35. Rapaport MK, Clary C, Fayard R, Endicort J. Quality of life impairment in depressive and anxiety disorders. Am J Psychiatry. 2005;162(6):1171-8.

36. Kessler RC, Foster CL, Saunders WB, Stang PE. Social consequences of psychiatric disorders. I: Educational attainment. Am J Psychiatry. 1995;152(7):102632 .

37. Kessler RC, Walters EE, Forthofer MS. The social consequences of psychiatric disorders. III: probability of marital stability. Am J Psychiatry. 1998;155(8):1092-6.

38. Spitzer RL, Kroenke K, Linzer M, Hahn SR, Williams JB, deGruy FV 3rd, Brody D, Davies M. Health-related quality of life in primary care patients with mental disorders. Results from the PRIME-MD 1000 Study. JAMA. 1995;274(19):1511-7.

39. Ormel J, Vonkorff M, Oldehinkel AJ, Simon G, Tiemens BG, Ustun TB. Onset of disability in depressed and non-depressed primary care patients. Psychol Med. 1999;29(4):847-53

40. Gazalle FK, Andreazza AC, Hallal PC, Kauer-Sant'anna M, Ceresér KM, Soares JC, Santin A, Kapczinski F. Bipolar depression: the importance of being on remission. Rev Bras Psiquiatr. 2006;28(2):93-6.

41. Berlim MT, Pavanello DP, Caldieraro MA, Fleck MP. Reliability and validity of the WHOQOL BREF in a sample of Brazilian outpatients with major depression. Qual Life Res. 2005;14(2):561-4.
42. Bagby RM, Ryder AG, Cristi C. Psychosocial and clinical predictors of response to pharmacotherapy for depression. J Psychiatry Neurosci. 2002;27(4):250-7. 